\title{
HOW EFFICIENT ARE AFRICAN SMALLHOLDERS? A CASE STUDY IN THE EASTERN CAPE PROVINCE OF SOUTH AFRICA
}

S.S. Ngqangweni ${ }^{1}$, J.F. Kirsten ${ }^{1}$ and C.L. Degado ${ }^{2}$

One of the aims of the South African government is to create higher income opportunities for the previously disadvantaged black community. In agriculture, this would involve reestablishing and supporting diverse forms of successful black agriculture. The main objective of this paper is to debate the issue of opportunity cost assumptions in the calculation of comparative advantage indicators for smallholders. This study reveals that these farmers can produce efficiently, even when subjected to opportunity cost assumptions that apply to their traditionally white commercial counterparts. Given additional prospects for strong linkages with the rest of the rural economy, speedy implementation of public investment programmes is warranted so as to level the playing field in the agricultural and rural economy

\section{INTRODUCTION}

The South African agricultural policy has, as one of its vision's core components, to create higher income and employment opportunities for resource-poor African farmers. This would involve, among other things, reestablishing and supporting diverse forms of successful black agriculture alongside a prosperous commercial sector. The future vision is, therefore, creation of a greater diversity in agriculture in terms of scale, socio-economic profile of participants, sources of livelihoods, factor and output mix, and technology. Such diversity will also entail building on linkages between agricultural and non-agricultural industries and between rural and urban sectors (Ministry for Agriculture and Land Affairs, 1998 and Duncan, 1999).

Given the history of repression of African smallholder farmers, it is expected that new policy measures will mostly affect this target group. However, relatively little is known about their economic dynamics on which to base policy decisions. More research is required outside the recent research on livelihoods (Lipton, et al, 1996), support programmes (Naledzani, 1992; Kirsten, 1994 and Singini \& Van Rooyen, 1995); and a database that the Development of Southern Africa regularly updates.

1 Department of Agricultural Economics, Extension and Rural Development, University of Pretoria, Pretoria 0002.

2 International Food Policy Research Institute (IFPRI), Washington, D.C., USA. 
As a result, the question is often asked whether smallholders are efficient and whether it is wise to use public funds to promote smallholder agriculture. A related question is: Do they use scarce resources efficiently and do they have a comparative advantage?

Recently, Ngqangweni, et al (1998) analysed the comparative advantage of smallholders in three South African provinces and Ngqangweni (2000) conducted further analysis on consumption linkages between agriculture and the rest of the rural economy in the Eastern Cape. This paper complements the above-mentioned research efforts by subjecting a sample of Eastern Cape smallholders to a series of efficiency tests. It emphasises the role of opportunity costs in shaping the efficiency of resource use.

\section{METHODOLOGY}

This study chose two commercial smallholder enterprises in the Eastern Cape, namely, indigenous beef and irrigated citrus. The estimation of efficiency required construction of Policy Analysis Matrices (PAMs) for each of the cases. Production of the basic indicators in PAM involved collection of production and marketing cost data through focus group interviews, farmer recall, and interviews with organisations involved in smallholder extension and marketing. The objective was to derive in each case farm budgets on a per unit basis, using prevailing technologies. This budget data could then be associated with secondary data on transportation costs, prices, and shadow prices, to assess partial equilibrium indicators of efficiency.

An important aspect in determining many of the PAM ratios is the estimation of social values for revenues and costs. This is the most difficult part of the research since if this is done incorrectly, the indicators would also be misleading. It is especially in relation to the social valuation of revenues and costs that a number of assumptions had to be made. These assumptions are an essential part of the analysis as they determine what values of land, labour and capital are the closest proxy of their opportunity costs for each activity. These opportunity costs in turn largely condition the outcome on whether or not an activity makes efficient use of resources.

This study takes a deliberate step in making the assumptions for valuation of domestic factors for black smallholder farmers in the Eastern Cape. In general, it assumes opportunity costs that are comparable to those of their white commercial counterparts. Given the history of smallholder repression and inequality of opportunity, it would probably not be fair to compare the two groups of farmers in this way. However, it was considered proper to 
determine how smallholder production would fare in terms of efficiency if it were to be subjected to the same cost assumptions as those faced by similar commercial farm activity. This would then expose the smallholders in an even more unambiguous fashion. These assumptions are summarised in Table 1 with the corresponding results of efficiency.

\section{INDICATORS OF EFFICIENCY OF RESOURCE USE}

In the PAM methodology, the DRC (domestic resource cost) ratio is the principal indicator of efficiency of resource use and, therefore, of the existence of comparative advantage in a farming activity.

A general overview of the results presented in Table 1 suggests that, under the given set of assumptions relating to opportunity costs, smallholders in the Eastern Cape produce both of the chosen commodities both profitably and efficiently. Although no intensive effort was taken to compare these farmers' efficiency with that of traditionally white large-scale commercial farmers, these results do expose very important findings in this regard. With a DRC ratio of 0.62 the indigenous beef activity boasts the better indicator of efficiency, followed by citrus at 0.65 . These assertions could not be considered conclusive without subjecting the data to further tests. Thus, for the purpose of expanding the scope of discussion, it was deemed appropriate to conduct a sensitivity analysis. It would only be interesting to determine how sensitive the above results are to the assumptions about opportunity costs.

Table 1: Contrasting outcomes from smallholder "private level" versus "commercial level" assumptions

\begin{tabular}{|c|c|c|c|c|c|c|}
\hline \multirow{2}{*}{ Activity } & \multicolumn{3}{|c|}{$\begin{array}{l}\text { "Private level" } \\
\text { Opportunity Cost } \\
\text { Estimates }\end{array}$} & \multicolumn{3}{|c|}{$\begin{array}{l}\text { "Commercial level" } \\
\text { Opportunity Cost } \\
\text { Estimates }\end{array}$} \\
\hline & $\begin{array}{l}\text { Land } \\
\text { (R/ha) }\end{array}$ & $\begin{array}{l}\text { Labour } \\
\text { (R/day) }\end{array}$ & DRC & $\begin{array}{l}\text { Land } \\
\text { (R/ha) }\end{array}$ & $\begin{array}{l}\text { Labour } \\
\text { (R/day) }\end{array}$ & $\overline{D R C}$ \\
\hline Indigenous Cattle & 12 & 10 & 0.37 & 30 & 20 & 0.62 \\
\hline Irrigated Citrus & 2900 & 30 & 0.79 & 2000 & 20 & 0.65 \\
\hline
\end{tabular}

\section{INTERPRETATION OF RESULTS INCLUDING THE OUTCOME OF SENSITIVITY ANALYSIS}

Table 1 contrasts outcomes from two scenarios, namely, one comparable to smallholder private costs versus one comparable to white commercial costs (Lyne, 2000; see also Ohene-Anyang, 1997). The "private-level" columns show 
data on land and labour costs, which approximate those reported or observed from the farmer's point of view, i.e. his private costs. They also show a resultant DRC when using these assumptions. Under the "commercial level" scenario, the opportunity costs of land and labour approximating commercial rates are recorded with their resultant DRC. These are discussed in more detail below as they apply to each of the chosen smallholder activities.

\subsection{Indigenous cattle}

Indigenous beef cattle farmers in the study area leased land from the state at a nominal rate of $\mathrm{R} 12$ per hectare. This is land transferred from the then Republic of South Africa to the former homelands, which subsequently became property of the South African Native Trust as stipulated by the Natives Trust and Land Act of 1936. The hired labour employed was paid a wage of R10 a day, which was considered as the market-related rate in the study area.

In the sensitivity analysis exercise (see Table 2 for results summary), the private level resource costs borne by the indigenous beef smallholder were taken as the first possible opportunity cost scenario. An additional factor was recorded as part of the first scenario, that is, an off-take rate of 16 percent was assumed. Using this scenario the smallholder farmers would enjoy superior comparative advantage as seen in a DRC of 0.37 . If higher opportunity costs (double the private level costs) are applied, the efficiency ratio rises to a less efficient but still impressive 0.44 , even after a higher and more likely ${ }^{1}$ off-take rate of 16 percent is used. This ratio is still safely lower than the threshold 1 above which comparative advantage is considered non-existent. Although the opportunity costs of land and labour play a role in determining smallholder comparative advantage in the Eastern Cape, such a role seems to be miniature. However, it should also be pointed out that land and labour opportunity costs seem to still play a relatively more important role than the quantity of output. The rest of the sensitivity analysis results show that smallholders will enjoy comparative advantage only up to a certain level of opportunity costs of land and labour. Even though no threshold level was measured, it seems that if land and labour opportunity costs were to increase up to R60 a hectare and R20 per day, respectively, society would no longer gain from smallholder use of resources in raising indigenous beef.

\subsection{Irrigated citrus}

Citrus farmers in the study area directly incur a cost of R2900 (rental from the state) per hectare for their land. The labour was observed to be $200 \%$ more 
Table 2: Sensitivity analysis: Indigenous cattle

\begin{tabular}{|c|c|c|c|c|c|c|}
\hline \multicolumn{6}{|c|}{ Scenario } & \multirow[b]{3}{*}{ DRC } \\
\hline \multirow[t]{2}{*}{$\#$} & \multicolumn{2}{|c|}{ Description } & \multicolumn{2}{|c|}{ Opportunity cost } & \multirow[b]{2}{*}{$\begin{array}{l}\text { Off-take } \\
\text { rate }(\%)\end{array}$} & \\
\hline & $\begin{array}{l}\text { Land } \\
\text { price } \\
\text { level }\end{array}$ & $\begin{array}{l}\text { Labour } \\
\text { price } \\
\text { level }\end{array}$ & $\begin{array}{l}\text { Land } \\
\text { (R/ha) }\end{array}$ & $\begin{array}{l}\text { Labour } \\
\text { (R/day) }\end{array}$ & & \\
\hline 1 & Low & Low & 12 & 10 & 16 & 0.37 \\
\hline 2 & Low & Low & 12 & 10 & 14 & 0.44 \\
\hline 3 & Low & High & 12 & 20 & 16 & 0.46 \\
\hline 4 & Low & High & 12 & 20 & 14 & 0.46 \\
\hline 5 & Medium & Low & 30 & 10 & 16 & 0.59 \\
\hline 6 & Medium & Low & 30 & 10 & 14 & 0.59 \\
\hline 7 & Medium & High & 30 & 20 & 16 & 0.62 \\
\hline 8 & Medium & High & 30 & 20 & 14 & 0.61 \\
\hline 9 & High & Low & 60 & 10 & 16 & 0.84 \\
\hline 10 & High & Low & 60 & 10 & 14 & 0.84 \\
\hline 11 & High & High & 60 & 20 & 16 & 0.86 \\
\hline 12 & High & High & 60 & 20 & 14 & 1.90 \\
\hline
\end{tabular}

expensive than all the other activities chosen for analysis at R30 per day. Taking these observed conditions as the first (lower limit) scenario in the sensitivity analysis (see Tables 1 and 3 ), reveals that smallholder citrus in the study area would still enjoy a relatively comfortable level of comparative advantage. This is manifested in the DRC of 0.79 under this scenario. Further investigation revealed that opportunity costs of land and labour for smallholder citrus in the study area were R2000 per hectare and $\mathrm{R} 20$ per day, respectively. This scenario significantly improves the activity's efficiency by close to 20 percent. The DRC of 0.65 for smallholder citrus makes it the second best after that of indigenous cattle.

According to Table 3, none of the twelve scenarios considered for the sensitivity analysis tests showed lack of comparative advantage for smallholder citrus. These results also show that none of the factors applied in the sensitivity analysis, namely, land and labour opportunity costs, as well as export quantity, played a more dominant role than the other in shaping social profitability. However, one cannot underestimate the impact of a good citrus harvest, and therefore, a high export percentage. It is shown in Table 3 that, keeping the opportunity costs of land and labour constant, and adjusting 
export percentage up or down by 5 percent, tended to have at least an equal effect on the DRC. This is a pointer towards the danger of ignoring the output side and only concentrating on the input side. The only major threat to the output side are the incidences of hail that have been reported over the years, which have negatively affected export percentage. Other factors such as longterm cash flow and debt status should be factored in when interpreting these results.

Table 3: Sensitivity analysis: Citrus

\begin{tabular}{|c|c|c|c|c|c|c|}
\hline \multicolumn{6}{|c|}{ Scenario } & \multirow{3}{*}{ DRC } \\
\hline \multirow[b]{2}{*}{$\#$} & \multicolumn{2}{|c|}{ Description } & \multicolumn{2}{|c|}{ Opportunity cost } & \multirow[b]{2}{*}{$\begin{array}{c}\text { Export } \\
(\%)\end{array}$} & \\
\hline & $\begin{array}{c}\text { Land price } \\
\text { level }\end{array}$ & $\begin{array}{c}\text { Labour } \\
\text { price level }\end{array}$ & $\begin{array}{l}\text { Land } \\
\text { (R/ha) }\end{array}$ & $\begin{array}{l}\text { Labour } \\
\text { (R/day) }\end{array}$ & & \\
\hline 1 & High & High & 2900 & 30 & 60 & 0.79 \\
\hline 2 & High & High & 2900 & 30 & 65 & 0.74 \\
\hline 3 & High & Low & 2900 & 20 & 60 & 0.74 \\
\hline 4 & High & Low & 2900 & 20 & 65 & 0.69 \\
\hline 5 & Medium & High & 2000 & 30 & 60 & 0.75 \\
\hline 6 & Medium & High & 2000 & 30 & 65 & 0.69 \\
\hline 7 & Medium & Low & 2000 & 20 & 60 & 0.69 \\
\hline 8 & Medium & Low & 2000 & 20 & 65 & 0.65 \\
\hline 9 & Low & High & 1000 & 30 & 60 & 0.70 \\
\hline 10 & Low & High & 1000 & 30 & 65 & 0.65 \\
\hline 11 & Low & Low & 1000 & 20 & 60 & 0.64 \\
\hline$\overline{12}$ & Low & Low & 1000 & 20 & 65 & 0.60 \\
\hline
\end{tabular}

\section{DISCUSSION AND CONCLUSIONS}

In the context of increased attention paid to African farmers by policy makers, research needs to establish, among other things, economic justifications for public investment in this sector. This paper attempts to ascertain how efficient African smallholders are when subjected to different levels of (land and labour) opportunity cost assumptions. A general observation from the cases studied is that smallholders can produce efficiently. More specifically this study established that, even when they are subjected to opportunity cost scenarios similar to their better-resourced white commercial counterparts, African smallholders still demonstrate a good level of efficiency. Although no direct comparative analysis was conducted between the two sectors, it can be 
safely concluded that African smallholders could be at least as efficient as their white commercial neighbours.

More research effort needs to go into analysing potential linkages between the African smallholder sector and the rest of the rural economy. Through this it would be established whether or not, in the context of broader rural restructuring, investment in this sector has any potential for broader income and employment growth. Recent studies on linkages (see Ngqangweni, 2000) do encourage positive implementation of restructuring programmes with the main focus being investment in the needed physical and economic infrastructure in order to level the playing field in the agricultural and rural economy.

\section{NOTE}

1. A higher off-take rate would make more sense for the Nkone considering its physical advantages.

\section{REFERENCES}

DUNCAN, A. (1999). Throwing light on cats in the dark: Agricultural economists and the policy agenda in South Africa. Agrekon, 38(4):437-76.

KIRSTEN, J.F. (1994). Agricultural support programmes in the developing areas of South Africa. Unpublished Ph.D. Thesis. University of Pretoria, Pretoria.

LIPTON, M., DE KLERK, M. \& LIPTON, M. (1996). Land, labour and livelihoods in rural South Africa. Volume 2. Durban: Indicator Press.

LIPTON, M., ELLIS, F. \& LIPTON, M. (1996). Land, labour and livelihoods in rural South Africa. Volume 1. Durban: Indicator Press.

LYNE, M.C. (2000). Personal communication. University of Natal, Pietermaritzburg.

MINISTRY FOR AGRICULTURE \& LAND AFFAIRS. (1998). Agricultural policy in South Africa: $A$ discussion document. Pretoria: Ministry for Agriculture and Land Affairs.

NALEDZANI, A.T. (1992). The Farmer Support Programme and agricultural development in Venda. Unpublished PhD Thesis. University of Pretoria, Pretoria. 
NGQANGWENI, S., LYNE, M.C., HEDDEN-DUNKHORST, B, KIRSTEN, J.F., DELGADO, C.L. \& SIMBI, T. (1998). Indicators of competitiveness of South African smallholder farmers in selected activities. Johannesburg: LAPC/PCS.

NGQANGWENI, S. (2000). Promoting income and employment growth in the rural economy of the Eastern Cape through smallholder agriculture. Unpublished PhD Thesis. University of Pretoria, Pretoria.

OHENE-ANYANG, E. (1997). Comparative advantage and policy incentives for commercial maize and wheat production in South Africa. Unpublished MSc (Agric) Dissertation. University of Pretoria, Pretoria.

SINGINI, R. \& VAN ROOYEN, C.J. (eds.). (1995). Serving small-scale farmers: an evaluation of the DBSA's Farmer Support Programmes. Halfway House, Development Bank of Southern Africa. 